\title{
Tagging diversity in personal learning environments
}

\author{
Yiwei Cao • Dejan Kovachev $\cdot$ Ralf Klamma • \\ Matthias Jarke $\cdot$ Rynson W. H. Lau
}

Received: 17 December 2014/Revised: 29 January 2015/Accepted: 30 January 2015/

Published online: 1 March 2015

(C) Beijing Normal University 2015

\begin{abstract}
Tagging is a prevalent practice in the Web 2.0. It has been widely used to annotate different media like video. However, in personal learning environments (PLEs), tagging is supporting not only content indexing but also the self-regulated learning process consisting of different phases like planning, learning, and reflecting. In particular, in the reflection phase, tags support the organization of learning outcomes. We have researched the interrelations of learning content, learning processes, and learning phases to provide a comprehensive overview about diverse tagging behavior in PLEs like using multi-granular tagging, semantic tagging, community-based tagging, and expert-amateur tagging. We have exemplified these behaviors by the design, realization, and evaluation of a PLE for classical Chinese poetry.
\end{abstract}

Keywords Personal learning environment · Technology-enhanced learning · Game-based learning · Web 2.0 · Community of practice · Multimedia

\author{
Y. Cao $(\bowtie)$ \\ IMC AG, Saarbrücken, Germany \\ e-mail: yiwei_cao@yahoo.com \\ D. Kovachev \\ SAP Innovation Center, Potsdam, Germany \\ e-mail: dejan.kovachev@gmail.com \\ R. Klamma · M. Jarke \\ RWTH Aachen University, Aachen, Germany \\ e-mail: klamma@dbis.rwth-aachen.de \\ M. Jarke \\ e-mail: jarke@dbis.rwth-aachen.de \\ R. W. H. Lau \\ City University of Hong Kong, Kowloon Tong, Hong Kong \\ e-mail: rynson.lau@cityu.edu.hk
}




\section{Introduction}

Learning is the effective and only activity to improve one's knowledge and skills. Learning goals and learning processes differ from person to person very much. In the research area of technology-enhanced learning, thus, personal learning environments (PLEs) have emerged as a new approach to allow learners to gather information, to plan how to learn, to reflect on it, and to learn with other learners. Learners set their own learning goals, as well as manage, retrieve, and share learning resources in PLEs. Learners perform better with the support of selfregulated learning in PLEs than in a common learning management systems (LMS) for all (Grace and Butler 2005). Although the concept of personalized learning has been proposed and discussed since a long while, research in PLE is still a new sector. On the one hand, PLEs have complex requirements from diverse learner communities. Even school students are using PLEs all the time, e.g., their classrooms are equipped with PLEs of online labs (Govaerts et al. 2013). On the other hand, with the rapid rise of social software and Web 2.0, a great amount of new learning activities and resources have impacts on self-regulated learning processes.

Around the core of plan, learn, and reflect, self-regulated learning process repeats different learning phases in order to enhance learners' "learn to learn" skills. Learners start with defining learning profile, searching, and selecting learning resources. Learners then work out with the selected learning resources. They also reflect and react on strategies and achievements. This reflection information can be reused to revise their own learning profiles for the next round of learning phases. Thus, self-regulation degree will be increased (Nussbaumer et al. 2009). Nussbaumer et al. (2009) also define six self-regulated learning key activities consisting of goal setting, self-monitoring, self-evaluation, task strategies, help seeking, and time management which should be highly supported in PLEs.

On the Web 2.0 with many social network sites, tagging has become one of the most prevalent activities to annotate and manage online media. Tags are replacing keywords, labels, categories, or classifications used in the past. The $n$ to $m$ relationship between tags and media makes better media management and retrieval than the folder-like media management way (Weinberger 2007).

Although tags have been applied to PLEs as a general significant feature for E-learning 2.0 (Downes 2004), there is little research work on how tagging enhances PLEs related to different learning phases because of the following reasons. First, learners have their high individual requirements. Different learners build up different learner communities who have different learning interests. Second, processes conducted in PLEs for self-regulated learning are complex. Third, learning content needs to be dealt with at different levels in order to be well learned during learning processes.

Our research tackles the aforementioned problems through inventing and using different tagging approaches in PLEs. Five tagging approaches are systematically proposed. (1) Multi-granular tagging is applied to organize, learn, and reflect knowledge. (2) Community-based tagging takes learner communities into consideration and commsonomy is set up instead of folksonomy. (3) Semantic tagging 
enforces better learning resource management. (4) Expert-amateur tagging is suitable for learning reflection. (5) And multimedia tagging helps learners plan and learn with vivid images. We make a case study with classical Chinese poems (CCP) because of the complex learning requirements.

The research questions are addressed around the motivations and realization of tagging approaches to self-regulated learning on the following three aspects. We apply different tagging approaches accordingly:

- Self-regulated learning process: multimedia tagging,

- Self-regulated learners: community-based tagging and expert-amateur tagging, and

- Learning content: multi-granular tagging and semantic tagging.

The remainder of this paper is organized as follows. "A case study of CCP learning" section discusses the special aspects and complexities of CCP learning. While Web 2.0 tagging activities cannot meet the complex requirements of PLEs for CCP learning, different tagging approaches need to work together. "Orchestration of diverse tagging approaches" section pertains to concepts and design of various tagging approaches, including community-based, semantic, multi-granular, and expert-amateur tagging approaches. It also explains how they help learners selfregulate in learning. "Applying multi-granular tagging approaches to game-based CCP learning" section presents tagging approaches to adjusting learning content operations for game settings to enhance learners' learning fun. Based on a learning repertoire of Chinese Tang poems, "Prototype implementation" section and "Prototype evaluation" section present the implementation and the evaluation of the PLE prototype. "Related work" section discusses the state-of-the-art research. "Conclusions and future work" section summarizes this paper with an outlook at our ongoing research.

\section{A case study of CCP learning}

It is known that learners can tag or annotate learning content in PLEs. Tags connect learning resources with learners as well as learner communities. An in-depth analysis of the reasons behind is still missing. Thus, we select classical Chinese poem (CCP) learning as a case study, because CCP has the complexity in learning content and the variety in the learner communities. Application of different tagging approaches can be well demonstrated in self-regulated CCP learning.

\section{Background knowledge of CCP learning}

Poetry is collective wisdom and knowledge of mankind over a long history. Classical Chinese poems (CCP) are an important subcategory of classical Chinese text and contribute greatly to Chinese literature. As a crucial part of Chinese literature, Classical Chinese Poems are a valuable deposit of knowledge and civilization over 2000 years and reflects the variety of history, society, economics, 
philosophy, and languages (Liu 1966). Thus, it has influenced on all Chinesespeaking regions worldwide and provides important learning and research resources.

Several significant issues can be identified in current CCP learning. Some issues are even contradictory. On the one hand, CCP has been losing its attractiveness in Chinese-speaking communities worldwide in comparison to a hundred years ago. The reasons are multifold again. For example, the learning process by reciting CCP has been considered as a tedious learning task for children, compared to playing video games. CCP is not well spread outside Chinese-speaking regions despite its offerings of substantial Chinese knowledge over a long history. The learning barriers are high because of the difficulty of the Chinese language itself as well as missing access channels. In detail, the difficulty of learning CCP includes how to learn pronunciation of the characters, how to memorize the characters as words, how to grasp the meaning of the character-based words, how to compose of the words from single characters, and even how to write the characters.

On the other hand, the learner community who is interested in CCP has been widened in variety. Not only Chinese children learners but also Chinese adults and elderly people, foreigners, sinologists, etc., begin to show interest in learning CCP. Several main goals among others are to use $\mathrm{CCP}$ as a vehicle for Chinese language training, to raise Chinese culture awareness and to keep Chinese traditions alive. From the technical viewpoint, modern information technologies have not been applied well in CCP. Finally, there are certain learning processes for CCP. Usually, learners learn $\mathrm{CCP}$ through repeating a word or repeating a sentence, from a single word to a single sentence, to a single paragraph, and to a whole poem.

\section{Learner communities}

With regard to the specialties of $\mathrm{CCP}$, it is useful to observe how the learner communities look like in ancient China. Then, Classical Chinese Poems were the main learning content for students in private schools, the so-called Chinese Schools, which was the only location to have learning communities. The learning process of reciting CCP has been every part of Chinese poetry learning as well as Chinese language learning (Seaton 2006). This conventional poetry learning method has been used at all Chinese classes on all Chinese school levels.

In contemporary times, people who learn $\mathrm{CCP}$ with different aims do not have the same educational background. Their expertise may range from novice knowledge, such as children and foreigners, to experts, such as students and sinologists. Learners are distributed all over the world. A centralized learning environment cannot satisfy the requirements for CCP knowledge representation and distribution in many different types of media. We define here the four levels of expertise in CCP. The first level describes the novices and the foreigners who know a little Chinese and want to improve it by learning CCP, or do not know Chinese at all, but have interest in learning Chinese. The second level contains the people who have recited some CCP but do not understand the content of them, such as younger children. The third level contains the students who have learned much about CCP and grasped some CCP spirits or artistic concepts behind poems, even the Chinese 
history and culture behind CCP. The fourth level is the expert level such as sinologists. They research on CCP as their professions or as their hobbies.

In addition, Chinese language is a great barrier for people to learn poems. Language learners are often confronted with different problems during foreign language learning. First, they lack time for tedious language learning tasks. Second, foreigners may have cultural gaps. It is hard to grasp the exact meaning of a foreign language, if learners are not engaged with the learning material in the original language. Third, the semantic gaps may include the nuances between similar words and missing direct translations in learner's native language. Fourth, little support about organizing learning material is provided to learners. Mobile learners' context is often considered. On the contrary, the context of learning content is seldom taken into consideration for the user's learning process.

Within a PLE, it is needed to identify these learners with different knowledge degrees and with different learning performances. Quick learners can learn several things together within one platform, e.g., poems, history, and geography. Elaborating learners can learn knowledge with an in-depth expansion of different domains. In a self-regulated learning situation, learners of different profiles must be able to recognize each other's profiles to learn together. It is possible for learners on different levels to approach more knowledgeable learners to get more knowledge according to their learning goals. All these learners who aim to achieve their learning goals can be considered as amateurs of different degrees. On the contrary to so-called amateurs, experts can also be involved in PLEs to help learners learn learning content better and to help learners enhance their self-regulated learning skills.

In the Web 2.0, practices are bookmarking of web resources, commenting on existing content, rating of content and users, visualization of content metadata in tag clouds, building up folksonomies, and recommendations, etc. They are not specified for learner communities. Any learners need to manage their own learning interests, goals, and plans. A simple tag cannot fulfill the requirements to manage learners' profiles. Employing the concept of community of practice, community-based tagging approach and commsonomy proposed first in Klamma et al. (2007), which can play an important role. In addition, expert tags can be totally different than tags used by amateur (Klamma et al. 2009), which can also be useful for self-regulated learning.

\section{Learning content analysis for CCP}

Classical Chinese poems are a valuable but almost locked treasure chest of human wisdom and civilization since 2000 years. As mentioned before, classical Chinese poem learning is a tedious task. Poems reflect the ways of thinking in its language and its culture. Although poems can be remembered and are possible to be recited within a short period of time, it is still tedious to learn. First, the semantics of poems are quite difficult to be grasped. Second, it is easy to forget poems if they are not repeated for a while.

On the contrary, if we look at the problems from another angle. They turn poems to a constructive and interesting content to study, due to two essential 


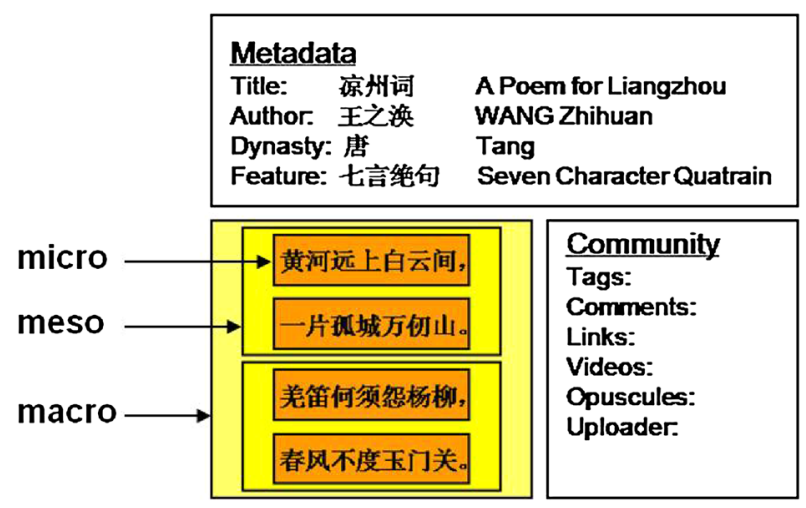

Fig. 1 The CCP content model

characteristics: conciseness and artistic concept. We explain them with one of the best classical Chinese poem collections, the Chinese Three Hundred Tang Poems (Harris 2009).

Chinese Tang Poems are composed with high conciseness. Each poem of this collection often contains several sentences. It is featured with certain ending syllable rhymes and consists of at least four lines of three characters, five characters or seven characters. Each sentence of the poem has a few characters. For example, the poem of five-character cut short verse has four sentences, i.e., 20 Chinese characters in all (see Fig. 1). However, this poem in such a short form contains highly compact content, such as description of landscapes, objects, people's life, and poets' feeling and thoughts. A translation variation is as follows: ${ }^{1}$

The Yellow River flows far between the white clouds,

A glimpse of a lone town amidst ten thousand mountains.

A flute plays the sorrowful tune of the willows,

The spring wind does not pass through the Yu Men Pass.

Due to conciseness, poems are an effective means for foreign language learning and culture and history learning. If Chinese is the native language or a target learning language, Chinese poems can be an effective and useful means. Consequently, the PLE should support to stress this feature of learning content, and to make good use of it. Thus, we identify that the way to use tags as used on the Web 2.0 cannot handle the multiple content levels of CCP. We propose a multigranular tagging approach in the next section.

The artistic concept is an image, a theme of a poem, and the complex experiences transferred through the poem composition. It may contain a variety of information including the objects described in the poem, the poet's feeling and thoughts, the natural and social environments of the poet. It is very difficult for language and

\footnotetext{
${ }_{1}$ http://chinese.hm68.com/index.php/chinese-poetry/170-liang-zhou-ci.
} 
poem learners to grasp artistic concepts behind the poem. In this case, learners are able to understand the meaning of each character in a poem, while they are not able to understand the whole poem. However, artistic concepts also have a positive effect for language learning. Understanding the poem helps learners improve their vocabulary greatly.

In this case that poems can be tagged with enhanced semantic-based tags would help learners grasp the artistic concepts well. Semantic-based tags (Klamma et al. 2007) are pairs of key words with a value mapping to a semantic time such as time and object, or even more detailed, animal and plant.

In the collection of Chinese Three Hundred Tang Poems, there are 311 poems composed by 77 authors in 4 composition periods and 7 writing types spanning from 618 to 907 A.D. The poems can be categorized by composition metadata including authors, composition period, and verse types. Thus, Chinese Tang Poems are diverse and convergent as concluded in Fig. 2.

The poem contents cover various content themes which can be grouped into different artistic concepts, e.g., time, date, season, weather, and object, as summarized in Table 1. A poem may contain many themes as listed in the table, for example, combining river, sun, mountain, sea, and tower. We also try to group the artistic concepts into MPEG-7 semantic tags (Kosch 2003) as an example.

This table just gives a rough number of poems related to different themes. Poets' feelings and thoughts vary greatly, which are omitted in this survey table. The themes also serve as a piece of context information for the learning content.

Learning context and multimedia analysis

Learning context is any information relevant to the interaction between a user and a learning environment (Denaux et al. 2005). Context usually consists of multiple partial descriptions of a situation including circumstances, objects, and conditions at each time instance. They are defined as context atoms (Korpipää and Mäntyjärvi

\begin{tabular}{|l|l|l|}
\hline Dimension & Metric & Poems \\
\hline \hline \multirow{3}{*}{ Author } & Wang Zhihuan (王之涣) & 2 \\
& Li Bai (李白) & 35 \\
& $\ldots$ & $\ldots$ \\
\hline \multirow{5}{*}{ Composition } & Beginning Tang (初唐, 618-712) & 13 \\
period & Flourishing Tang (盛唐, 713-765) & 171 \\
& Middle Tang (中唐, 766-835) & 75 \\
& Late Tang (晚唐, 836-907) & 55 \\
& Unknown & 7 \\
\hline \multirow{5}{*}{ Writing type } & five-character-ancient-verse (五言古体诗) & 35 \\
& seven-character-ancient-verse (七言古体诗) & 28 \\
& five-character-quatrain (五言绝句) & 29 \\
& seven-character-quatrain (七言绝句) & 51 \\
& five-character-regular-verse (五言律诗) & 80 \\
& seven-character-regular-verse (七言律诗) & 53 \\
& folk-song-styled-verse (乐府) & 45 \\
\hline
\end{tabular}

Fig. 2 Diversity of Three Hundred Tang poems 
Table 1 A categorization of Chinese Tang Poems in terms of content themes

\begin{tabular}{|c|c|c|c|}
\hline Semantic & Context & Theme & Poems \\
\hline \multirow[t]{10}{*}{ Time } & \multirow[t]{3}{*}{ Time } & Early morning & 24 \\
\hline & & Night fall & 35 \\
\hline & & Night & 85 \\
\hline & \multirow[t]{3}{*}{ Date } & Winter solstice & 1 \\
\hline & & Double-seventh festival & 2 \\
\hline & & Moon festival & - \\
\hline & \multirow[t]{4}{*}{ Season } & Spring & 68 \\
\hline & & Summer & 10 \\
\hline & & Autumn & 58 \\
\hline & & Winter & 66 \\
\hline \multirow[t]{5}{*}{ Concept } & \multirow[t]{5}{*}{ Weather } & Sunny & 7 \\
\hline & & Cloudy & 87 \\
\hline & & Windy & 105 \\
\hline & & Raining & 56 \\
\hline & & Snow & 26 \\
\hline \multirow[t]{6}{*}{ Location } & \multirow[t]{6}{*}{ Location } & Tower & 32 \\
\hline & & Ship & 27 \\
\hline & & Home town & 42 \\
\hline & & River & - \\
\hline & & Sea & - \\
\hline & & Mountain & - \\
\hline \multirow[t]{7}{*}{ Agent } & \multirow[t]{7}{*}{ Person } & Female & 20 \\
\hline & & Male & 19 \\
\hline & & Youth & 33 \\
\hline & & Senior & 30 \\
\hline & & Friend & 6 \\
\hline & & Parent & 9 \\
\hline & & Brother & - \\
\hline \multirow[t]{12}{*}{ Object } & \multirow[t]{6}{*}{ Life form } & Flower & 102 \\
\hline & & Plant & 68 \\
\hline & & Horse & 43 \\
\hline & & Bird & 30 \\
\hline & & Fish & 8 \\
\hline & & Forest & - \\
\hline & \multirow[t]{6}{*}{ Object } & Moon & 103 \\
\hline & & Sun & 60 \\
\hline & & Wine & 61 \\
\hline & & Candle & 11 \\
\hline & & Musical instrument & 9 \\
\hline & & Gourmet & - \\
\hline
\end{tabular}


2003). Then, we have the learning context composed by learning context atoms, i.e., time, date, poem title, poem author, poem themes, poem keywords, and learners' mobile device information.

Similar to the term situated learning, context-aware learning platforms focus more on learners' context or users' learning behaviors. Learners can select different things to learn according to their context, which is also an important prerequisite for self-regulated learning.

In addition, learning content also has context. For example, Tang poems are concise and rich of artistic concepts, which are associated with context information as well. Figure 3 depicts context consisting of learning content context as well as learners' context. Contexts such as location and time can be mapped to various artistic concepts. Location-based information is mostly used for location relevant content learning.

Additionally, we consider extensive multimedia usage for self-regulated learning. Multimedia is a powerful auxiliary learning material which sets up another context dimension (Spaniol et al. 2003). Using multimedia, we can present a poem in a vivid and expressive way. It helps learners understand learning objects in combination with both the conciseness of learning objects and learners' language knowledge. In order to relate most appropriate multimedia items to learning objects, we need the bidirectional mapping mechanism between them. One learning object can be mapped to different multimedia items at the same time regarding different themes and vice versa.

An appropriate correlation between context of learning content and learners is depicted in Fig. 3. Learners' context information includes physical environments such as time, location, and season which match the artistic concept of the poems correspondingly. Meanwhile, learning content has its context which can be observed as poems themselves and their related multimedia data. Metadata, user-generated tags, and poems' difficulty levels belong to poem context.

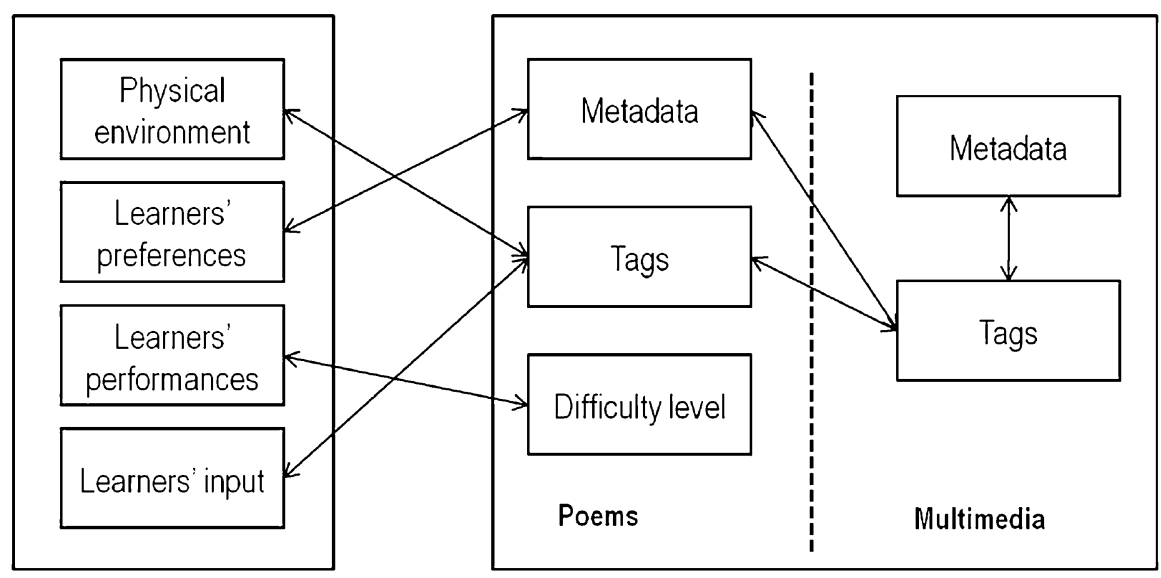

Context of learners

Context of learning content

Fig. 3 Mapping between learning content context and learners' context 
Given a mapping example between context atoms of both learning objects and multimedia items, the image with context "location" and value "Yellow River" is matched to the learning poem "Ascending the Stork Tower" whose "location" context is "Yellow River" as well. The context information is especially difficult for foreigners to learn the poem. The word "Stork" in the poem title is related to location instead of the real object stork.

In summary, mappings of different contexts can be applied to discover the relationship between users, poems, or multimedia items.

1. Mapping from learners to poems: we find poems which context information has the same value or intersected value set as user's context. For example, if User A preferred authors are Wang Zhihuan and Li Bai, then the poem Ascending the Stork Tower composed by Wang Zhihuan can be assigned to User A.

2. Mapping from multimedia items to poems: we find poems whose context atom has same values or intersected value set as multimedia items context atom. For example, if a multimedia item is tagged with "Yellow River" and "Yangtze River," then the poem Ascending the Stork Tower with tags "Yellow River" and "sunset" can be tagged with the multimedia item as well.

3. Mapping from poems to multimedia items: vice versa, we find multimedia items whose context atoms have the same values or intersected value set as poems and "sunset," then the multimedia item with tags "Yellow River" and "Yangtze River" can be associated with the multimedia item.

Here, we discuss about context, multimedia, and tags. In fact, we can also consider context and multimedia items as two additional tagging approaches for CCP. The geo-tagging approach connects resource to its related geographic location. Together with temporal tagging, they are referred to context-aware tagging approaches. Multimedia tagging can add either diverse user-generated multimedia items or certain predefined multimedia items to learning content. The advantages of applying multimedia tagging approaches include that learning contents can be simply illustrated and quickly annotated.

\section{Orchestration of diverse tagging approaches}

Web 2.0 technologies make it possible for users to upload a great number of learning resources for poems. Learning resources including videos and images can be found in many Web 2.0 sites. With this access to Web 2.0 media, learners do not have new methods but perform the usual learning method, though the learning activities of users with different learning profiles are different. We explore tagging as a new approach to self-regulated learning procedures.

The combination of different tagging approaches is based on two assumptions from previous discussions. First, the simple Web 2.0 tagging approach alone cannot meet the requirement of complex procedures for self-regulated learning. Different tagging approaches can fulfill this task together. Second, context awareness in PLEs is embedded both in the learners' context as well as in the context of learning 
content. Tagging approaches can map the context issues for self-regulated learning. Five types of tagging approaches are discussed in the following parts.

Formalization of diverse tagging approaches

\section{- Multi-granular tagging}

Resource contents are linked to each other. Moreover, one content may contain another as well according to their different sizes. For example, a weblog entry may have text, several images, and one video.

The content can be divided into three scales and follows the rule below:

$$
\text { Microcontent } \subseteq \text { Mesocontent } \subseteq \text { Macrocontent. }
$$

The same resource can belong to different resource containers which refer to the content scales above. We use $x, y, z$ to differentiate the variables.

$$
R_{x}^{\mathrm{mi}} \subseteq R_{y}^{\mathrm{me}} \subseteq R_{z}^{\mathrm{ma}}
$$

Targeting at different scales of resource contents, we may define three levels of tagging activities accordingly: micro tagging, meso tagging, and macro tagging. A tag assigned to the content scale accordingly:

$$
t_{x}^{\mathrm{mi}} \rightarrow r_{y}^{\mathrm{mi}}, t_{x}^{\mathrm{me}} \rightarrow r_{y}^{\mathrm{me}}, \quad \text { and } \quad t_{x}^{\mathrm{ma}} \rightarrow r_{y}^{\mathrm{ma}} .
$$

The tags follow this rule: $t_{x}^{\mathrm{mi}} \subseteq t_{y}^{\mathrm{me}} \subseteq t_{z}^{\mathrm{ma}}$.

\section{- Community-based tagging}

The community aspect leads to the concept commsonomy from folksonomy. We identify that different user communities use different tags for the same resources. Commsonomy refers to a group of tags or annotations for resources created, organized, and shared by users in a user community (Klamma et al. 2008).

Given a community as $(U, T, R, C), U$ is a set of users, $T$ is a set of tags, $R$ is a set of media resources, and $C$ is the community platform.

In case that user $u_{z}$ tags a resource:

$$
t_{x}^{c} \rightarrow r_{y}^{c} \quad \text { if } \quad u_{z} \in c_{y} .
$$

\section{- Expert-amateur tagging}

In addition, experts usually use different tags from amateurs. We specify the tag set of experts $T^{e x}$ which is highly associated with taggers' expertise degree. Taggers refer to users who conduct tagging activities.

- Semantic tagging 
Semantic operations give certain tags to resource. Tags are a set of $T=\left(t_{1}, t_{2}, \ldots, t_{n}\right)$. Semantic operations use tags as a basis for metadata standardbased tags. Semantic tagging is to annotate a resource with a set of tags from a predefined semantic base:

$$
t_{x} \rightarrow r_{y}, s_{z} \quad \text { where } \quad s_{z} \in S .
$$

Thus, semantic tagging consists of a triple $\left(t_{x}, s_{z}, r_{y}\right)$.

- Multimedia tagging

Multimedia tagging assigns another multimedia $m$ item to a resource, instead of a simple text-based tag. $m_{x} \rightarrow r_{y}$ then predefined tags for the multimedia can be passed to resources. Multimedia tagging is transitive.

If $t_{z} \rightarrow m_{x}$ additionally, then $t_{z} \rightarrow r_{y}$.

Tagging framework in PLEs

In PLEs, the miscellaneous property of tags (Weinberger 2007) in use is able to represent the great variety of learning resources. We propose to apply different tagging approaches for PLEs in order to organize learning resources, help learners learn and share within communities (see Fig. 4). The usual Web 2.0 tagging model (Marlow et al. 2006) has the components of users, tags, and resources as depicted in the upper-right part of Fig. 4. In regard to the Web 2.0 tagging model, we combine different tagging approaches and represent them into a tagging framework for self-

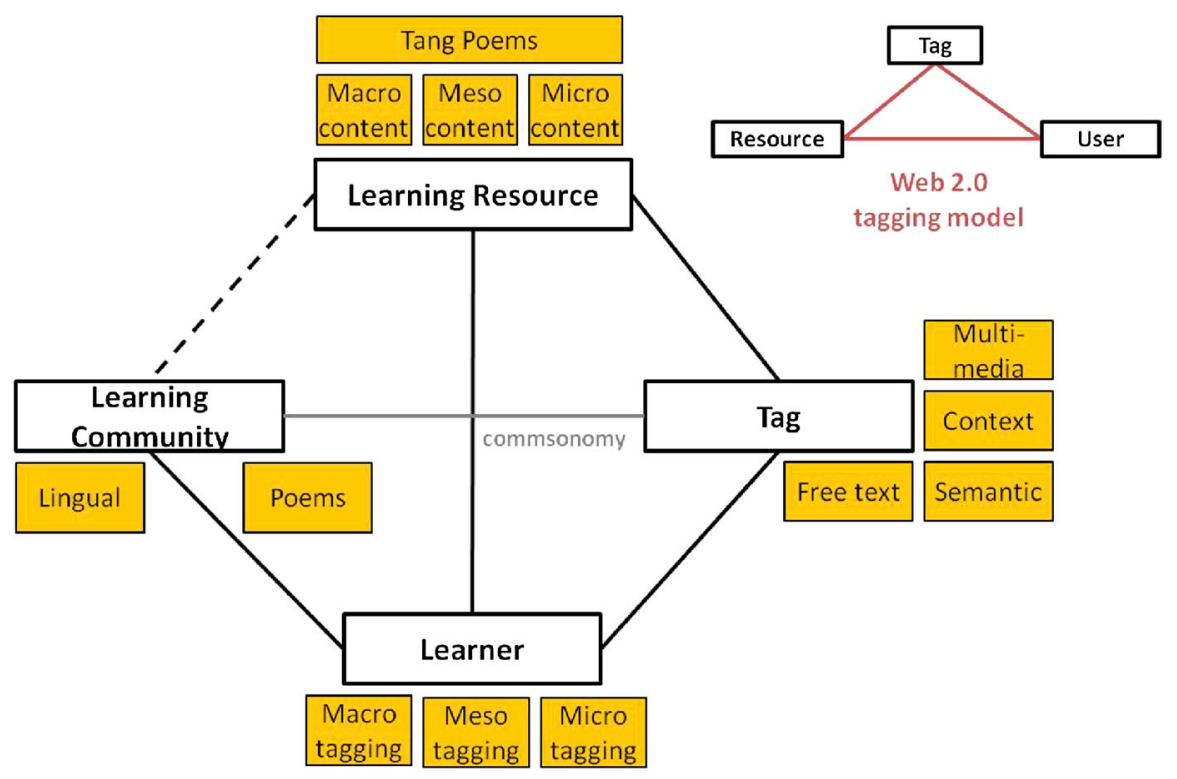

Fig. 4 A tagging framework combining different tagging approaches 
regulated learning with flexible organization of learning resources, learners' profile, and learner communities.

Learners use tags represented in free- or semi-controlled keyword vocabularies, or in semantic concepts and links. The context refers to the inner context of learning resource based on learning content analysis as well as the external context of learners' learning activities and their communities. In general, we have two classes of learning context, i.e., inner context and external context. Inner context is used to group and classify learning objects, i.e., the context-related information of one learning resource. For example, time, date, and device are external contexts, while the others of the aforementioned poem artistic concepts are inner context. The external context has been identified in mobile computing and e-learning domains (Abowd et al. 1999; Lieberman and Selker 2000), usually reflecting the surrounding environment of learners.

Learners tag learning resources on different levels including macro, meso, and micro, while learning resources also have this granularity. Micro tagging is suitable for a single word or character. A single frame of videos is often tagged. Meso tagging is performed on sentence or paragraph level. Video clips of a duration are often tagged with more than one tag. Macro tagging is applied on paragraphs or whole poems. The whole video of a poem may include meso and micro tagging methods.

In PLEs, the learners' community influences learning processes (Wenger 1998). Staying in a community of language learning, poetry learning, or culture learning can help learners specialize in their learning content with the assistance of commsonomy or expert-amateur tagging.

Moreover, these different tagging approaches can be applied in an interweaving way. If two of them are applied to annotate one resource, we consider that the tags build up a two-dimensional tag space. When more than two approaches are applied, the tag space is multi-dimensional, then

$$
t_{x}^{\text {space }}=\left(t_{h}^{c}, t_{j}^{m_{i}}, s_{k},\left(m_{l}, t_{l} *\right), \exp _{n}\right)
$$

denotes a tag assigned to a resource and possessing the possible highest dimensions. This tag may be a community-specific tag, belonging to $m_{i}=$ one from macro, meso, or micro, connecting to a semantic group, equal to another multimedia item which can be with or without additional tags and the tagger's expertise degree.

Diverse tagging approaches to self-regulated learning

In Table 2, we summarize and explain how those different tagging approaches can be employed in the different self-regulated learning phases including planning, learning, and reflecting (Nussbaumer et al. 2009) appropriately. In some cases, the tagging approaches are not relevant and denoted as “-”. They are based on and abstracted from the user's experiences and the survey of the existing systems in Table 3 in "Related work" section. 
- In the planning phase, tagging itself is the main activity to annotate learning content.

- In the learning phase, tags can be applied to assist gaming design and to make some comparisons. Comparison of learning content is an efficient learning process.

- In the reflection phase, tags can be used for rating learning performances and to help learners recap content learned.

\section{Applying multi-granular tagging approaches to game-based CCP learning}

In order to support self-regulated learning, educational games are integrated to enhance the learners learning interest and "nonlinear" learning interactions. The aforementioned multi-granular tagging approach is the basis to conceptualize a series of content model and game operations in this section.

Table 2 Different tagging approaches for self-regulated learning

\begin{tabular}{|c|c|c|c|c|}
\hline $\begin{array}{l}\text { Innovations } \\
\text { in tagging / } \\
\text { Learning } \\
\text { phases }\end{array}$ & $\begin{array}{l}\text { Learner } \\
\text { profile } \\
\text { management }\end{array}$ & $\begin{array}{l}\text { Search, prepare, } \\
\text { and plan (tagging } \\
\text { and } \\
\text { recommendation) }\end{array}$ & $\begin{array}{l}\text { Learning (gaming and } \\
\text { comparisons) }\end{array}$ & $\begin{array}{l}\text { Reflection (rating, } \\
\text { recap, and } \\
\text { recommendation) }\end{array}$ \\
\hline $\begin{array}{l}\text { Self- } \\
\text { regulated } \\
\text { learning } \\
\text { activities }\end{array}$ & $\begin{array}{l}\text { Goal setting, } \\
\text { task } \\
\text { strategies }\end{array}$ & $\begin{array}{c}\text { Task strategies, } \\
\text { help seeking }\end{array}$ & $\begin{array}{l}\text { Help seeking, time } \\
\text { management, self- } \\
\text { monitoring }\end{array}$ & $\begin{array}{l}\text { Self-monitoring, self- } \\
\text { evaluation }\end{array}$ \\
\hline $\begin{array}{l}\text { Multi- } \\
\text { granular }\end{array}$ & $\begin{array}{l}\text { Goal setting, } \\
\text { task } \\
\text { strategies }\end{array}$ & $\begin{array}{l}\text { Tagging learning } \\
\text { resource details } \\
\text { on different } \\
\text { content levels }\end{array}$ & $\begin{array}{l}\text { Tagging learning } \\
\text { process activities, } \\
\text { interpretation, } \\
\text { translation, learning } \\
\text { game design }\end{array}$ & $\begin{array}{l}\text { Rating performance } \\
\text { related to learning } \\
\text { resource details, } \\
\text { ranking learning } \\
\text { resources }\end{array}$ \\
\hline $\begin{array}{l}\text { Community- } \\
\text { based }\end{array}$ & $\begin{array}{l}\text { Community } \\
\text { profile } \\
\text { management }\end{array}$ & $\begin{array}{l}\text { Select and } \\
\text { organize based } \\
\text { on community } \\
\text { interest }\end{array}$ & $\begin{array}{l}\text { Compare community's } \\
\text { learning suggestions }\end{array}$ & $\begin{array}{l}\text { Comparison of } \\
\text { community's learning } \\
\text { performance }\end{array}$ \\
\hline Semantic & Goal setting & $\begin{array}{l}\text { Categorization and } \\
\text { classification of } \\
\text { learning } \\
\text { resources }\end{array}$ & $\begin{array}{l}\text { Semantics of learning } \\
\text { resources }\end{array}$ & $\begin{array}{l}\text { Categorization and } \\
\text { classification, recap }\end{array}$ \\
\hline $\begin{array}{l}\text { Expert- } \\
\text { amateur }\end{array}$ & $\begin{array}{l}\text { Task } \\
\text { strategies }\end{array}$ & $\begin{array}{l}\text { Recommendation, } \\
\text { help seeking }\end{array}$ & $\begin{array}{l}\text { Comparison of learners' } \\
\text { own tags and expert } \\
\text { tags }\end{array}$ & $\begin{array}{l}\text { Rating, } \\
\text { recommendation }\end{array}$ \\
\hline Multimedia & $\begin{array}{c}\text { Avatars for } \\
\text { learners }\end{array}$ & $\begin{array}{l}\text { Labeling and } \\
\text { categorizing } \\
\text { difficulties or } \\
\text { learning content }\end{array}$ & Fun & $\begin{array}{l}\text { Recap, } \\
\text { recommendation }\end{array}$ \\
\hline
\end{tabular}


Table 3 A survey of tagging systems for learning

\begin{tabular}{|c|c|c|c|c|}
\hline $\begin{array}{l}\text { Innovations in } \\
\text { tagging / learning } \\
\text { phases }\end{array}$ & $\begin{array}{l}\text { Learner profile } \\
\text { management }\end{array}$ & Search, prepare, and plan & Learning & Reflection \\
\hline Free text & $/ /$ & Delicious & $/ /$ & $/ /$ \\
\hline Multi-granular & $/ /$ & SeViAnno & CCPLE & // \\
\hline Community-based & YouTell, SeViAnno & SeViAnno & CCPLE & $/ /$ \\
\hline Semantic & $\begin{array}{l}\text { YouTell, SeViAnno, } \\
\text { ROLE Language, } \\
\text { iTag }\end{array}$ & $\begin{array}{l}\text { SeViAnno, AnViAnno, } \\
\text { ROLE Language, } \\
\text { P-TAG }\end{array}$ & $/ /$ & $\begin{array}{l}\text { ROLE } \\
\text { Language }\end{array}$ \\
\hline Context-aware & MobCamp & AnViAnno & $\begin{array}{l}\text { ROLE } \\
\text { Language, } \\
\text { TagSense }\end{array}$ & $/ /$ \\
\hline Expert-amateur & YouTell, SeViAnno & YouTell, SeViAnno & $/ /$ & $/ /$ \\
\hline Multimedia /image & Avatar profile picture & NMV & $/ /$ & $/ /$ \\
\hline Game-based & - & Inversion-problem game & Taboo & $\begin{array}{l}\text { Inversion- } \\
\text { problem } \\
\text { game }\end{array}$ \\
\hline
\end{tabular}

The usual successive learning method is that learners learn CCP through repeating from a single word to a single sentence, to a single paragraph, and to a whole poem. According to the learning process, an abstract model for CCP is a three-scale model consisting of micro, meso, and macro scales. The example given in Fig. 1 also illustrates how a Classical Chinese Poem is split with those three levels. And it also illustrates the metadata and learning community-related information. Both can be handled as context information as discussed in "A case study of CCP learning" section.

- On the micro scale, a poem is a collection of single Chinese characters. Micro content consists of character units.

- On the meso scale, a poem is decomposed into short sentences ended by a unique punctuation. Meso content consists of sentence units.

- On the macro scale, a poem is decomposed into paragraphs as a certain block (20 or $50 \%$ ) of the poem or even the poem as a whole. Macro content consists of paragraph units.

The content scales fulfill the following rule:

Micro scale content $\subseteq$ Meso scale content $\subseteq$ Macro scale content.

The operations on CCP learning contents can be defined on three levels correspondingly: paragraph permutation (macro operations), sentence permutation (meso operations), and character permutation (micro operations). Performing these operations, learners can learn CCP by playing games. A game setting can be specified based on the three main operations (see Fig. 5), which have the following relationship among themselves. This is the other way around to the aforementioned content scale. 
Micro operations $\subseteq$ Meso operations $\subseteq$ Macro operations.

Learners can select a content level at first. On the macro scale, macro operations can be performed, while micro operations are performed on the micro scale correspondingly. With this flexible combination of content scales and operation scales, users can select learning content according to their learning profiles and preferences. Learning difficulty is raised from the micro-micro to the macro-micro combination.

The learning content $\mathrm{CCP}$ is decomposed into three content levels as well: macro, meso, and micro. Granularity on the content level helps learners organize their learning content and learning process via playing games. The tagging activities are performed on Classical Chinese Poems at three levels based on the context-aware tagging model (see Fig. 5).

Based on these multi-granular operations, users can play with single characters and can learn CCP from any sentence or character within the whole poem paragraph. Figure 6 shows how learners grasp a poem with meso operation on macro content and micro operation on meso content (cf. the CCP content model in Fig. 1). The difficulty level is different as well. The latter is more difficult because learners need to learn each character and their permutation at the same time. This game can also run on smartphones so that learners can learn CCP anywhere at any time.

\section{Prototype implementation}

The aforementioned tagging approaches reflect both the game settings for learning processes and the multimedia annotation and tagging for learning content organization. The benefits of multi-granularity have been proven in PLE design with game settings. Learners are enabled to adjust their learning processes onto different difficulty levels through game settings based on macro, meso, and micro levels of learning content for self-regulated learning. The three levels of learning

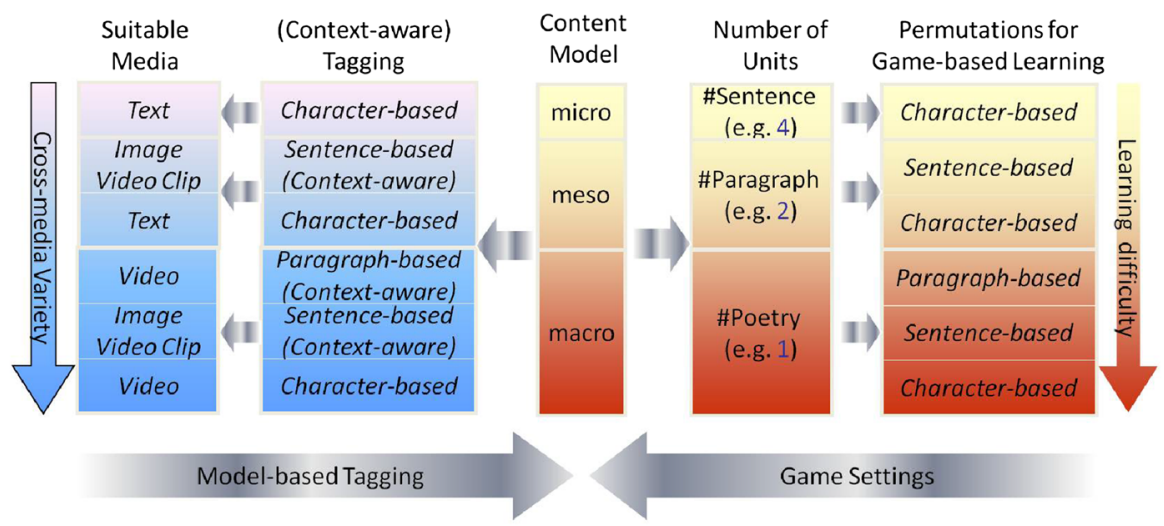

Fig. 5 Learning resource tagging on macro, meso, and micro levels 

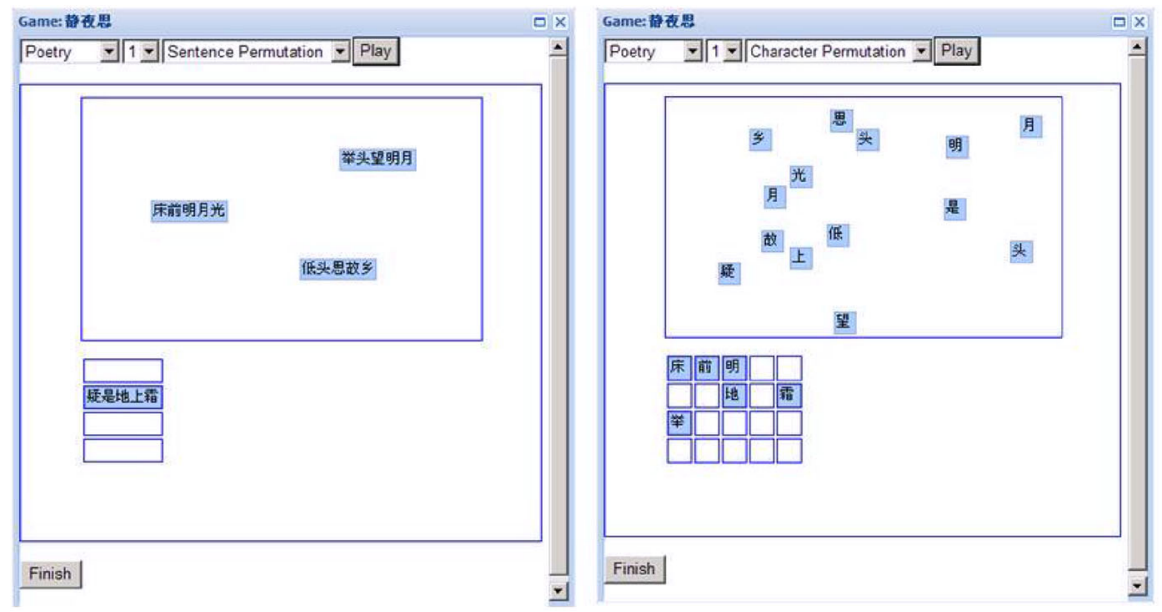

Fig. 6 The screenshots for CCP learning games

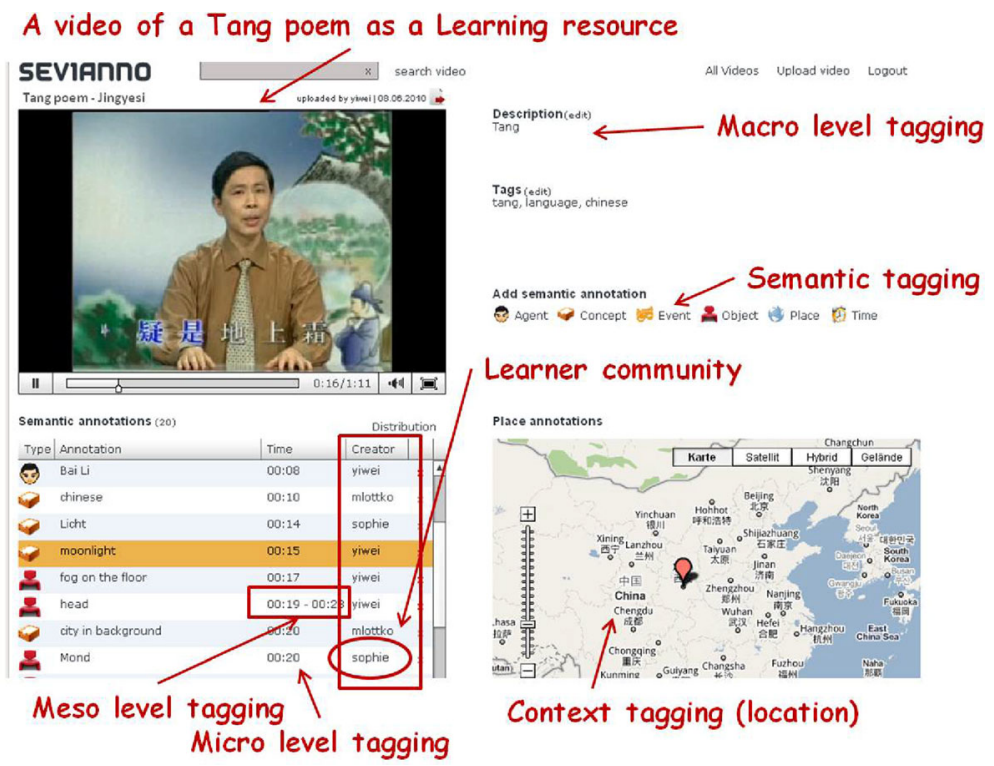

Fig. 7 A PLE prototype for Chinese learning via poem tagging

multimedia annotation help learners find, organize, reflect, and assess learning content.

The application of various tagging approaches is realized in the prototype SeViAnno (Renzel et al. 2010). SeViAnno also supports users to upload poems with metadata and videos about the poem or various videos with translation versions. Figure 7 shows how a poem from the collection of Chinese Three Hundred Tang 
Poems is learned and how language learning is integrated through annotating videos. Learners are able to tag the learning content with semantic tags. Semantic tags used to annotate Chinese poems consist of Agent, Object, Concept, Place, Time, and Event. The artistic concept of poems can be added in this way. The subartistic concept like time, date, and season can be tagged in the semantic tag time or event. Furthermore, object and agent can be used to express what is described in poems. Different learners can have different interpretations to the same learning material.

Learning content-based communities can be observed here as language learner communities, poem learner communities, history learner communities, and so on. For each community, different levels can be specified such as beginners, amateurs and experts. For example, a beginner learns Chinese via a Tang poem and gives tags to the video clips. The multi-granular tags from three different levels help him/her learn the vocabularies. For the poetry learner communities, the multi-granular tags can help poetry learners understand learning content intensively. In addition, within the learner communities, community-based tags and expert tags can be applied for learners to search, plan, organize, and reflect learning content. Different semantic tags according to predefined concepts are applied to enhance semantics of learning content or users.

At the same time, the multi-granular tagging approach is applied for game operations. With regard to CCP gaming module, the realization of the prototype CCPLE focuses on learner communities' requirements in order to help users learn CCP with mobility and with fun. CCPLE is implemented using Java to make the program portable. A set of Google Web Toolkit (GWT) tools is applied to support user interaction well. GWT is an open source Java software development framework for web application development. It is featured with a Java-to-JavaScript Compiler, so that the whole realization of both client and server sides use Java. It allows web developers to create AJAX applications in Java. GWT-based applications are supported automatically in various web browsers.

In CCPLE, learners can search and select poems for learning by gaming. The game difficulty can be chosen with the flexible combination of content scale and operation scales in order to match the users' learning profiles.

After learners finish playing a game session, they can get feedback from the platform what learning achievement they have obtained. All achievement results are also traced and displayed in a grid panel. Learners' user names, game difficulty levels, and time for accomplishing games are listed to the learner community.

The metadata storage uses XML data format and XML database technology. Metadata of classical Chinese poems include poem title, author (poet), dynasty, feature ranging from 3-character to 7-character or writing style name. Similarly, metadata can also be given in many languages besides Chinese. CCP can be modeled in XML with tags like $\langle$ poetry $\rangle$, 〈paragraph $\rangle,\langle$ sentence $\rangle$, and $\langle$ character $\rangle$.

The CCP learning content is stored in the Oracle $10 \mathrm{~g}$ database which supports Unicode very well. The GWT Remote Procedure Call (RPC) mechanism is employed to enable the client side to invoke codes on the server side. 


\section{Prototype evaluation}

The evaluation process for PLE is an open dynamic cycle. Web 2.0-based PLEs are difficult to evaluate considering diverse learner communities. What learners learn and how they learn need to be adapted to individual learners. Learners should have the tools and methods to control their own learning processes.

This cycle can be staged in three measure phases which interact on the next one in a loop (see Fig. 8). (1) Learner profiles are defined and revised, while learners input their goals and preferences. Evaluation measurements include learners' previous learning achievements in the PLE. The learner finds and selects learning resources by creating PLE or from recommendations from peers or tutors. Learners need to have the control on what they prefer to learn. In the Chinese Tang Poem learning system, learners select and organize the poems with macro tagging issues. (2) Learners work on selected learning resources for assessment and self-assessment to attain skills using different learning events. In our case, game-based, annotation (e.g., meso and micro tagging) or other effective approaches can be applied and evaluated. (3) Learners reflect and react on strategies, achievements, and usefulness via evaluation and self-evaluation or feedback from different sources. Learners should be able to compare their learning achievements of different time periods and different strategies. In our case, teachers or tutors can collaborate on the three tagging levels to help learners learn and get better achievements.

Multi-granular tagging is useful at learn and reflect phases. The distribution of the semantic tags in Fig. 9 shows that Concept, Object, and Event in MPEG-7 semantic base types are the most favorite tag classes for classical Chinese poems. Prevalent concept tags are "nostalgia," "home sickness," and "recap," while prevalent object tags include "moon," "river," "home town," "mountain," and event tags like "sunset." These tags help learners grasp "visionary" poem content.

Finally, let us recall the requirements for language learning PLEs from "Orchestration of diverse tagging approaches" section. First, incorporation of multi-granular tagging and game settings effectively compromises learners' lack of

Fig. 8 Tags can be applied at each learning phase in PLE design

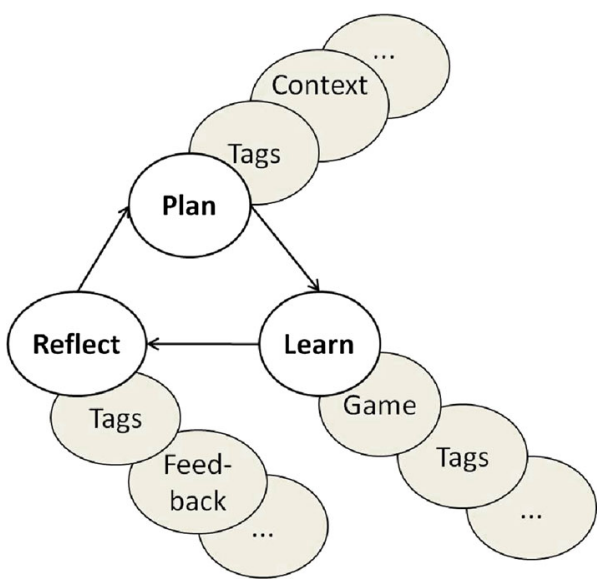


time. Second, one of the most effective means to bridge cultural gaps is to use videos and other forms of multimedia, and involve community efforts. Third, semantic tagging helps learners tag learning content with different focuses and organize and self-assess what they have learned.

The CCPLE was tested with about 50 people with different educational backgrounds. We prepared a questionnaire for the learners, but after the evaluation period, only 17 questionnaires were returned. We can report that, besides the language, lacking experience with Web 2.0 technologies is still a barrier, even among computer science students. Among those, 14 were native Chinese speakers and only 7 were also learning CCP before. Interestingly, 14 had never used a Chinese language learning platform before, and 12 even had never used an e-learning platform at all. Although 14 learners heard about the Web 2.0, only 8 had ever used Web 2.0 tools to experience different forms of learning. The functionality of the prototype is limited, so learners expect more new functions available in future. Some of them would like to produce video for CCP themselves. Editing multimedia for CCP is a tedious process and not supported by any learning platform so far. Usually, a video consists of a meaningful animation of the content, a highquality audio recording of the citation of the poem, and some appropriate music track. There are no meaningful results about learning in communities, yet. Future research will cover community-based evaluation of learning success. But, for this evaluation, we need access to more learning communities.

\section{Related work}

The state-of-the-art tagging approaches and PLEs are surveyed as below. Then, we compare several existing tagging approaches for self-regulated learning. PLEs for $\mathrm{CCP}$ and language learning are briefly surveyed to support the aforementioned case study of CCP learning.

\section{Tagging approaches}

With the advent of user-generated content on the Web 2.0, much research has been done related to tags, tagging systems, tagging models, tagging motivations, and tagging algorithms, build-up of folksonomy, etc. Surveys of various existing tagging models conducted in Hales (2008), Marlow et al. (2006), Budiu et al. (2009) show
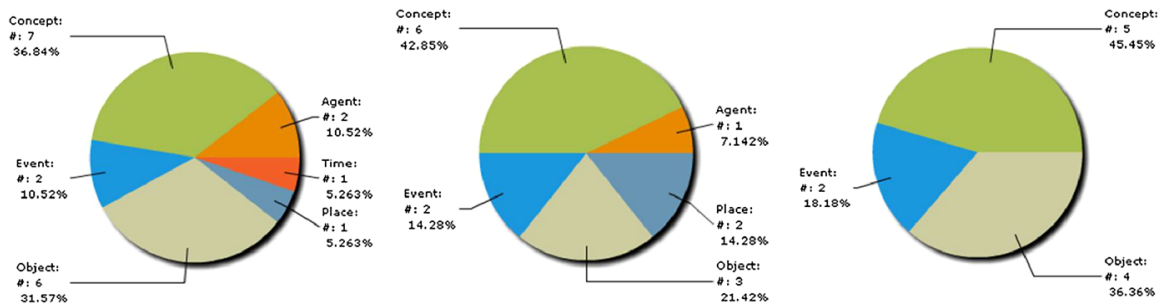

Fig. 9 Distribution of semantic tags for three Chinese Tang Poems 
that model constructions are based on collaboration enhancement and on different tagging activities or behaviors. Tagging motivations are identified as collective and collaborative information management and sharing in the research (Ames and Naaman 2007; Kröll et al. 2010; Zollers 2007). Marinho et al. (2010) conclude several tagging methods including social tagging, experts tagging, game tagging, and mined tagging. Their conducted comparison shows that each tagging method has its own advantages and disadvantages. One tagging method alone cannot perform some complex tasks.

The application domains of tagging have a wide spectrum. Some surveys are done for learning resource management in technology-enhanced learning, knowledge management, as well as enterprise applications (Bateman et al. 2007; Millen et al. 2005). Tagging systems for learning often differentiate expert tags and learner tags, and aim to enhance tagging in a collaborative way. Although there has been research conducted to explore tagging and learning goals (Krenge et al. 2011), the most relevant tagging research work just focuses on learning resource management, rather for the planning phase than for other learning processes. Learning resources are classified into images, links, documents, etc. The sub-content of learning resources cannot be tagged separately.

Automatic tagging methods have been surveyed. Among them, three prototypes are highly interesting and represent stereotypes called P-TAG (Chirita et al. 2007), iTAG (Strohmaier et al. 2009), and TagSense (Qin et al. 2011). iTAG demonstrates the idea of intent tagging which explores the goals behind the applied tags. Experiments were conducted in some e-commerce web sites. It covers a small aspect of tagging motivations and can be only applied for learning goals setting for self-regulated learning. P-TAG focuses on personalized automatic tag generation for web resources based on personal desktop document management behavior. TagSense uses context data collected by mobile phones and sensors to tag photos automatically, based on some simple context reasoning rules. These technologies pave the way for tagging approaches to learning material organization.

Personal learning environments

The idea of PLE was initially discussed in 2001 by Olivier and Liber (Olivier and Liber 2001; van Harmelen 2006). PLEs help people control and arrange their own learning processes and provide support to set their own learning goals (Downes 2007). Thus, managing content and processes as well as communication with others in the process of learning are possible, too. Learners have more power in controlling the learning environment than before. However, little systematic research has been carried out to analyze the learning content and identify users' self-regulated learning needs. There are only a few PLEs which take advantage of a great amount of available multimedia materials on the Web 2.0 or even incorporate educational gaming approaches.

Little interactive learning mechanisms or other new means are developed to stimulate learners' interest, to help learners learning poetry quickly, or to reach out to a wider range of learner communities. According to some pedagogues, most learning is informal (Cross 2007). Online learning communities and online knowledge repositories are the core of the current network-based informal learning 
environments. Media technologies allow a wide variety of activities and experiences, which can support language learning. How to manage and promote the informal learning in communities is still an open research question.

PLEs support individuals to establish one's own suitable learning services connecting with the global ecology of Internet services, e.g., blogs, links, wikis, social software, and RSS feeds. Rather than integrating tools within a single context, the system should focus on coordinating connections between users and a wide range of services instead.

Web 2.0 sites aiming at a wide community do not provide this possibility. A generic collection of available Web 2.0 tools and aggregated information sources can serve as learning. If we take a close look at the newspaper web site of New York Times, ${ }^{2}$ we find a set of tools and approaches to learning languages. Users after login can collect articles with multimedia files into their profiles and recommend to other users through various Web 2.0 sites, e.g., Facebook or Delicious. These operations are not specific enough to meet with goals and activities of the learner communities. However, the existing Web 2.0 tools cannot meet the special learning needs of learners or support the complex self-regulated learning processes in PLEs including good planning, learning, and reflecting activities.

\section{Summary of tagging approaches for self-regulated learning}

Today, the technologies and tools supporting learners to produce content have made rapid proliferation possible. Downes (2004) coined the term e-Learning 2.0 which is derived from e-Learning concepts in combination with the Web 2.0 (O'Reilly 2005). On the one hand, social software such as Flickr, YouTube, and SlideShare help users create and share contents. On the other hand, social software assists users to adopt new ways of managing knowledge and improving efficiency, such as with RSS, tags, and social bookmarking.

To support effective organization of information in PLEs, mechanisms of flexible tagging with sharing facilities are needed. Tagging represents learning activities, where the tagger, e.g., sums up a series of words into one or more summary tags, each of which stands on its own to describe some aspects of the resource based on the tagger's experiences and beliefs (Marlow et al. 2006; Smith 2008). Tagging has been a common way of organizing content for further content navigation, filtering, or search. This enables to index particularly subjective forms of information where full-text searching is either not possible or not useful (Golder and Huberman 2006). Furthermore, collaborative tagging is a feature of many Web 2.0 services, where it is known also as social tagging. In PLEs, collaborative tagging has great potentials to further enrich interactions and awareness (Bateman et al. 2007).

Another important aspect of PLE and tagging is context. An application or system is context-aware if it uses context to provide relevant information or services to the user, where relevancy depends on the user's task (Abowd et al. 1999). A PLE that adapts according to the learner's context enhances the learning performance.

\footnotetext{
${ }^{2}$ http://www.nytimes.com/.
} 
The next generation of learning services will take advantage of the innovative IT technology including mobile smartphones, e-book readers, tablets with different physical sensors and better data exchange capabilities that will not only keep track of the learner's PLE, but can also track learner's context, and thus anticipate learner's intentions. For example, a context-aware mobile learning scenario introduced in Klamma et al. (2006) shows a mobile multimedia platform support to a smart city guide adapted to different stereotypes, including architecture students, pilgrims, and wellness-interested people. Learners are able to learn different cultural aspects about a city according to their own interests.

The widgets we have realized in our previous work demonstrate their functions for potential usage in PLE design. We select SeViAnno (Renzel et al. 2010) and its mobile version AnViAnno, CCPLE (Cao et al. 2009), YouTell and MobCamp (Cao et al. 2010), ROLE Language Widgets (Wolpers et al. 2010), iTag (Strohmaier et al. 2009), P-TAG (Chirita et al. 2007), TagSense (Qin et al. 2011), and some inversion-problem games (e.g., Taboo) introduced in Ahn and Dabbish (2008) as listed in Table 3. Tagging is not well applied for reflection phase.

\section{CCP learning}

CCP makes important learning material at the Chinese lecture in classroom situations. The traditional CCP learning model is a community of practice, which is a group of people who share a concern or a passion and do interact regularly to improve (Wenger 1998). A CCP community has some mutual engagements such as reciting CCP or learning Chinese. They build up a joint enterprise using a shared repertoire. Community members are informally bound by common activities like participation and reification. Educational gaming can be well integrated to empower participation within CoP (Spaniol et al. 2008).

There are several mobile applications systems as PLEs for Chinese poetry and language learning, e.g., Mandarin quotes from Tang poems ${ }^{3}$ or collected edition of poems from Tang and Song dynasty (see Fig. 10). They provide learning of Chinese Tang Poems after selecting poem category, such as sadness, happiness, and encouragement. Users can learn the poem by viewing image and listening to the vocal translator. The advantage is that user can learn the poem which is correspondent to user's category choice. However, it is not allowed to extend the keywords through user tagging. The goal is to tell learners what the poem content is about. The poem sentences are handled as a whole, and no single phrase or word can be pointed out and explained precisely. Thus, existing Chinese poem learning does not make good use of the characteristics of learning resources.

Language learning, especially second language acquisition, has been a permanent topic for a life-long personal competence improvement within the accelerated globalization paces (Segler et al. 2002; Littlewood 1981). Hanauer (2001) showed how poetry and language learning have similarities and interact on each other. Poem language is used for its esthetic and evocative qualities, in addition to its meaning

\footnotetext{
${ }^{3}$ http://itunes.apple.com/de/app/mandarin-quotes-from-tang/id355500168?mt=8.
} 

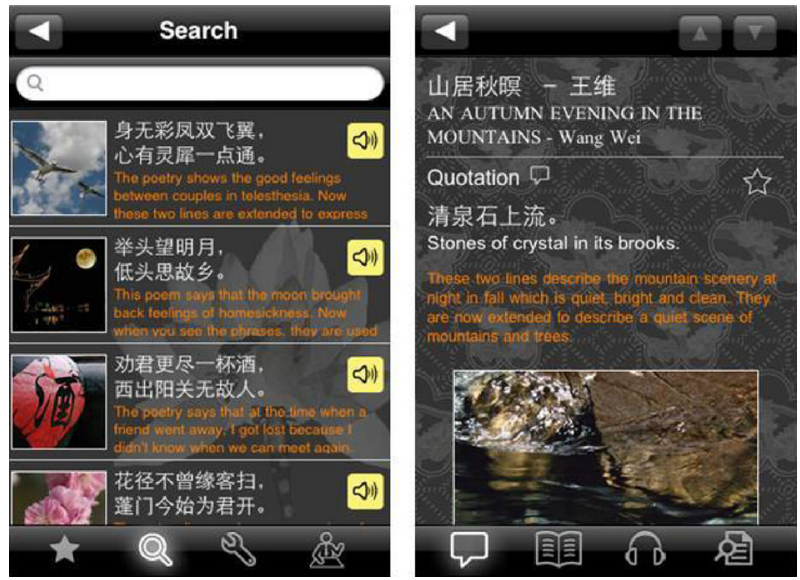

Fig. 10 An existing iPhone CCP learning application

(Widdowson 1975). For language learners, the task of poetry reading can develop their knowledge of the target language by providing a context within which their language resources are enriched and applied to the understanding of new and maybe unusual uses of linguistic and semantic forms. The complexity of constructing meaning in poems pushes language learners to apply their previously acquired language knowledge in order to create meaning (Culler 1975). Furthermore, it enlarges language learners' needs to communicate and collaborate with other learners using rich multimedia materials and a rich repertoire of interactive means (Ellis 1995).

However, there are few PLEs targeted to both poem and language learning. There are a series of mobile applications applying context information for language learning through, e.g., situational conversations in YouCoy. ${ }^{4}$ However, PLEs for poem learning use rarely comprehensive context information. Traditionally, poem learning has been a fixed procedure. New mobile applications should involve context of learning content.

Mainly, a systematic learning model lacks in CCPLE. In summary, an in-depth learning content analysis is missing in all these existing systems. Language learning and poem learning have not been observed together to help learners enhance linguistic expression power. It is nearly impossible to achieve interoperability or exchangeability of CCP learning content across different platforms now.

\section{Conclusions and future work}

Learner communities have various requirements on profile management, learning planning, learning process support, and self-reflection in order to conduct selfregulated learning. Thus, we applied various tagging approaches to support each phase of self-regulated learning in PLEs.

\footnotetext{
${ }^{4}$ http://www.yocoy.com/i-You/.
} 
The tagging approaches are applied in several aspects. Learning content, metadata, and communities need an in-depth analysis both on the semantic and the context levels. Learning resource context has been additionally explored in our research, besides services' context and learners' context. The Web 2.0 sites including YouTube videos are integrated as learning resources. Educational games with multiple difficulty levels motivate learners to learn. The tagging model is applied to capture features of learning content for gaming design on the macro, meso, and micro scales as well. This generic tagging model facilitates learning content exchange between different platforms.

To prove the concept, a PLE prototype is realized with poem and language learning as the learning goal. Chinese Tang Poems are taken as a case study due to the substantial poem patterns, the richness of its historic and cultural aspects, and the conciseness of the poem languages. Based on the combinations of various tagging approaches, gaming design, and the best collection of Chinese Tang Poems, we demonstrate how a PLE for CCP and language learning is realized.

We have mainly realized the multi-granular tagging, community-based tagging, and semantic tagging. Multimedia tagging and expert-amateur tagging approaches need to be integrated in future. In addition, further functionalities such as contextaware learning content delivery or recommendation, automatic context extraction based on the poem model, and learning achievements evaluation based on the tagging model will make this Chinese Tang Poem learning platforms more useful for language learning in future. It is also necessary to conduct more user studies to evaluate the prototype. Context-aware both on the content level and on the learners' behaviors will be an important component to augmented reality, which is a new trend for PLEs identified by the New Media Consortium (Johnson et al. 2011). They made a survey of new trends and research challenges in technology-enhanced learning. They gave a time line of mobile learning, game-based learning, and learning analytics ranging from the recent one year to four-to-five years in the near future (Johnson et al. 2011). Our research on CCP learning also shows the integration of various advanced technologies to assist learning to learn CCP.

Finally, ancient knowledge or culture is also raising new problems and conflicts by the rapid development of technologies. Technologies are shaping the interactions of communities in a way which may be conflicting with the traditional knowledge itself. Learning with new technologies may also deepen the understanding of and revitalize old knowledge for our times. Hence, it is challenging to discover the potentials of advanced information technologies for preserving and developing traditional knowledge such as poetry.

\section{References}

Abowd, G. D., Dey, A. K., Brown, P. J., Davies, N., Smith, M., \& Steggles, P. (1999). Towards a better understanding of context and context-awareness. HUC '99: Proceedings of the 1st international symposium on handheld and ubiquitous computing (pp. 304-307). London, UK: Springer.

Ames, M., \& Naaman, M. (2007). Why we tag: Motivations for annotation in mobile and online media. Proceedings of the SIGCHI conference on human factors in computing systems (pp. 971-980). New York, USA: CHI'07, ACM. doi:10.1145/1240624.1240772. 
Bateman, S., Brooks, C., McCalla, G., \& Brusilovsky, P. (2007). Applying collaborative tagging to e-learning. In Proceedings of the workshop on tagging and metadata for social information organization at 16th international world wide web conference, May 7, 2007.

Bateman, S., Brooks, C., \& McCalla, G. (2007, May). Applying collaborative tagging to e-learning. In Proceedings of the 16th international world wide web conference (WWW2007), Banff, Alberta: Canada.

Budiu, R., Pirolli, P., \& Hong, L. (2009). Remembrance of things tagged: How tagging effort affects tag production and human memory. Proceedings of CHI 2009, April 3-9, 2009 (pp. 615-624). Boston, USA: ACM.

Cao, Y., Klamma, R., Gao, Y., Lau, R.W., \& Jarke, M. (2009) A Web 2.0 personal learning environment for classical Chinese poetry. In ICWL '09: Proceedings of the 8th international conference on advances in web based learning (pp. 98-107). Berlin, Heidelberg:Springer.

Cao, Y., Klamma, R., \& Jarke, M. (2010). Mobile multimedia management for virtual campfire-the german excellence research cluster UMIC. International Journal on Computer Systems Science and Engineering (IJCSSE), 25(3), 251-265.

Chirita, P. A., Costache, S., Handschuh, S., \& Nejdl, W. (2007). P-TAG: Large scale automatic generation of personalized annotation tags for the web. Proceedings of the 16th international conference on World Wide Web. WWW'07 (pp. 845-854). New York, NY, USA: ACM. doi:10.1145/ 1242572.1242686.

Cross, J. (Ed.). (2007). Informal learning. San Francisco: Pfeiffer.

Culler, J. D. (1975). Structuralist poetics: Structuralism linguistics and the study of literature. London: Routledge and Kegan Paul.

Denaux, R., Dimitrova, V., \& Aroyo, L. (2005, July 24-29) Integrating open user modeling and learning content management for the semantic web. In Proceeding 10th international conference on user modeling (UM 2005). (pp. 9-18). Scotland, UK: Springer.

Downes, S. (2004). Educational blogging. Educause Review, 39(5) (September/October 2004), http:// www.educause.edu/ero/article/educational-blogging. Accessed 20 Feb 2015.

Downes, S. (2007). Learning networks in practice. Emerging Technologies for Learning, 2, 19-27.

Ellis, R. (1995). Interpretation tasks for grammar teaching. TESOL Quarterly, 29(1), 87-105.

Golder, S., \& Huberman, B. A. (2006). Usage patterns of collaborative tagging systems. Journal of Information Science, 32(2), 198-208.

Govaerts, S., Cao, Y. C., Vozniuk, A. V., Holzer, A., Garbi Zutin, D., San Cristobal Ruiz, E., Bollen, L., Manske, S., Faltin, N., Salzman, C., Tsourlidaki, E., \& Gilet, D. (2013). Towards an online lab portal for inquiry-based stem learning at school. In Proceedings of the 12th international conference on web-based learning. ICWL'13, Springer.

Grace, A., \& Butler, T. (2005). Learning management systems: A new beginning in the management of learning and knowledge. International Journal of Knowledge and Learning 1(1/2), 12-24, http:// www.inderscience.com/filter.php?aid $=6248$

Hales, D. (2008). Understanding tag systems by comparing tag models. In B. Edmonds, K. G. Troitzsch, \& C. H. Iglesias (Eds.), Social simulation: Technologies, advances and new discoveries (pp. 68-80). Hershey: IGI Global.

Hanauer, D.I. (2001). Task of poetry reading and second language learning. Applied Linguistics22(3), 295-323. http://applij.oxfordjournals.org/cgi/content/abstract/22/3/295

Harris, P. (Ed.). (2009). Three hundred Tang poems (everyman's library pocket poets). New York: Everyman's Library.

Johnson, L., Smith, R., Willis, H., Levine, A., \& Haywood, K. (2011). The 2011 horizon report. Tech. rep. The New Media Consortium.

Klamma, R., Cao, Y., \& Jarke, M. (2009). Storytelling on the web 2.0 as a new means of creating arts. In B. Furht (Ed.), Handbook of multimedia for digital entertainment and arts (pp. 623-650). New York: Springer.

Klamma, R., Cao, Y., \& Spaniol, M. (2008). Smart social software for mobile cross-media communities. In M. Granitzer, M. Lux, \& M. Spaniol (Eds.), Multimedia semantics: The role of metadata, studies in computational intelligence (Vol. 101, Chap. 5, pp. 87-106). Berlin: Springer. doi:10.1007/978-3540-77473-0_5.

Klamma, R., Spaniol, M., Cao, Y. (2006, October). Community aware content adaptation for mobile technology enhanced learning. In W. Nejdl \& K. Tochtermann (Eds.), Innovative approaches to learning and knowledge sharing, In Proceedings of the 1st European conference on technology 
enhanced learning (EC-TEL 2006), Hersonissou, Greece, October 1-3 (Vol. 5227, pp. 227-241). Berlin: LNCS.

Klamma, R., Spaniol, M., Renzel, D. (2007, September 5-7). Community-aware semantic multimedia tagging-from folksonomies to commsonomies. In K. Tochtermann, H. Maurer, F. Kappe \& A. Scharl (Eds.), Proceedings of I-Media'07, international conference on new media technology and semantic systems (pp. 163-171). J.UCS (Journal of Universal Computer Science) Proceedings, Graz, Austria: Springer ( 2007).

Korpipää, P., \& Mäntyjärvi, J. (2003). An ontology for mobile device sensor-based context awareness. In Proceedings of 4th international and interdisciplinary conference on modeling and using context 2003 (pp. 451-459) LNAI 2680, Springer.

Kosch, H. (2003). Distributed multimedia database technologies supported by MPEG-7 and MPEG-21. Boca Raton: CRC Press.

Krenge, J., Petrushyna, Z., Kravcik, M., \& Klamma, R. (2011). Identification of learning goals in forumbased communities. In: Proceedings of the 11th international conference on advanced learning technologies (ICALT 2011), July 6-8, Athens, Georgia, USA. p. to appear. IEEE Computer Society.

Kröll, M., Körner, C., Strohmaier, M. (2010). itag: Automatically annotating textual resources with human intentions. Journal of Emerging Technologies in Web Intelligence2(4), http://ojs. academypublisher.com/index.php/jetwi/article/view/0204333342

Lieberman, H., \& Selker, T. (2000). Out of context: Computer systems that adapt to, and learn from context. IBM Systems Journal, 39(3\&4), 617-632.

Littlewood, W. (1981). Communicative language teaching: An introduction. Cambridge: Cambridge Univiversity Press.

Liu, J. J. (1966). The art of Chinese poetry. Chicago: The University of Chicago Press.

Marinho, L. B., Nanopoulos, A., Schmidt-Thieme, L., Jäschke, R., Hotho, A., Stumme, G., et al. (2010). Social tagging recommender systems. In F. Ricci, L. Rokach, B. Shapira, \& P. B. Kantor (Eds.), Recommender systems handbook (1st ed.). New York: Springer.

Marlow, C., Naaman, M., Boyd, D., \& Davis, M. (2006, August 22-25). Ht06, tagging paper, taxonomy, flickr, academic article, to read. In HYPERTEXT 2006, proceedings of the 17th ACM conference on hypertext and hypermedia (pp. 31-40). Odense, Denmark. doi:10.1145/1149941.1149949.

Millen, D., Feinberg, J., \& Kerr, B. (2005). Social bookmarking in the enterprise. Queue, 3, $28-35$. doi:10.1145/1105664.1105676.

Nussbaumer, A., Fruhmann, K., Albert, D., Ferdinand, P., Kiefel, A., Kirschenmann, U., Ullrich, C., Wills, S., Mikroyannidis, A., von Der Heiden, B., Werkle, M., Naeve, A. (2009). Role deliverable 6.1: Common psychopedagogical framework. 1.1 edition.

Olivier, B., \& Liber, O. (2001). Lifelong learning: The need for portable personal learning environments and supporting interoperability standards. Tech. rep., The JISC Centre for Educational Technology Interoperability Standards, Bolton Institute.

O'Reilly, T. (2005). What is web 2.0 -design patterns and business models for the next generation of software. Tech. rep., www.oreillynet.com. Retrieved July 3, 2006 from http://www.oreillynet.com/ pub/a/oreilly/tim/news/2005/09/30/what-is-web-20.html

Qin, C., Bao, X., Roy Choudhury, R., \& Nelakuditi, S. (2011). Tagsense: A smartphone-based approach to automatic image tagging. In Proceedings of the 9th international conference on mobile systems, applications, and services (pp. 1-14). , New York, NY, USA: MobiSys '11, ACM, doi:10.1145/ 1999995.1999997.

Renzel, D., Cao, Y., Lottko, M., Klamma, R. (2010, May 19-20). Collaborative video annotation for multimedia sharing between experts and amateurs. In A. Carreras, J. Delgado, X. Maronas, V. Rodrìguez (Eds.), Proceedings of the 11th international workshop of the multimedia metadata community on interoperable social multimedia applications (WISMA-2010). vol. CEUR workshop proceedings (pp. 7-14). Barcelona, Spain: CEUR Workshop Proceedings.

Seaton, J. (2006). The Shambhala anthology of Chinese poetry. Boston: Shambhala Publications.

Segler, S. M., Pain, H., \& Sorace, A. (2002). Second language vocabulary acquisition and learning strategies in ICALL environments. Computer Assisted Language Learning, 15(4), 409-422.

Smith, G. (2008). Tagging-people-powered metadata for the social web. Berkeley: New Riders.

Spaniol, M., Cao, Y., Klamma, R., Moreno-Ger, P., Fernández-Manjón, B., Sierra, J.L., Toubekis, G. (2008). From story-telling to educational gaming: The bamiyan valley case. In ICWL '08: Proceedings of the 7th international conference on advances in web based learning (pp. 253-264). Berlin, Heidelberg: Springer. 
Spaniol, M., Klamma, R., \& Jarke, M. (2003). ATLAS: a web-based software architecture for multimedia e-learning environments in virtual communities. In W. Zhou, P. Nicholson, B. Corbitt, \& J. Fong (Eds.), Advances in web-based learning, proceedings of ICWL 2003, Melbourne, Australia, August 18-20. LNCS (Vol. 2783, pp. 193-205). Berlin Heidelberg: Springer.

Strohmaier, M., Kröll, M., \& Koerner, C. (2009). Automatically annotating textual resources with human intentions. In Proceedings of the 20th ACM conference on Hypertext and hypermedia (pp. 355-356) HT'09, New York, NY, USA: ACM, doi:10.1145/1557914.1557986.

van Harmelen, M. (2006, July). Personal learning environments. In Proceedings of 6th international conference on advanced learning technologies (ICALT'06) (pp. 815-816). Kerkrade: The Netherlands.

von Ahn, L., \& Dabbish, L. (2008). Designing games with a purpose. Communications of the ACM, 51, 58-67. doi:10.1145/1378704.1378719.

Weinberger, D. (2007). Everything is miscellaneous. New York: Times Books.

Wenger, E. (1998). Communities of practice: Learning, meaning, and identity. Cambridge: Cambridge University Press.

Widdowson, H. G. (1975). Stylistics and the teaching of literature. London: Longman Group Ltd.

Wolpers, M., Friedrich, M., Shen, R., Ullrich, C., Klamma, R., Renzel, D. (2010). Early experiences with responsive open learning environments. In K. Tochtermann \& H. Maurer (Eds.), Journal of universal computer science (J.UCS), proceedings of I-KNOW 2010, Graz, Austria (pp. 391-402), September, 2010.

Zollers, A. (2007) Emerging motivations for tagging: Expression, performance, and activism. In Tagging and metadata for social information organization workshop, WWW07.

Yiwei Cao holds a diploma and doctoral degree in computer science from RWTH Aachen University, and a bachelor degree in architecture from Tongji University, Shanghai. She was working on the research excellence cluster UMIC at the Chair for Information Systems at RWTH Aachen. Currently, she works on an EU research project in technology enhanced learning (Go-Lab) at IMC AG in Saarbrücken. She serves as PC member and peer reviewer for many conferences and journals in TEL. Her research interests are community information systems focusing on applications in technology enhanced learning, cultural heritage management, multimedia storytelling, and social network analysis.

Dejan Kovachev is currently working on big data enterprise applications at the SAP Innovation Center in Potsdam, Germany. He holds a doctoral degree in computer science from RWTH Aachen, where he was affiliated with the Chair for Information Systems at RWTH Aachen, the B-IT Research School of Bonn-Aachen International Center for Information Technology and the research excellence cluster "Ultra High Speed Mobile Information and Communication" (UMIC). Before that, he earned his diploma degree in computer science and engineering from the Ss. Cyril and Methodius University in Skopje, Macedonia. His research interests lie on the intersection of mobile multimedia and cloud computing.

Ralf Klamma holds diploma, doctoral and habilitation degrees in computer science from RWTH Aachen University. He leads the research group "advanced community information systems" (ACIS) at the information systems chair, RWTH Aachen University. He is coordinating and working in major EU projects for Technology Enhanced Learning (Learning Layers, SAGE and BOOST). Ralf organized doctoral summer schools and conferences in Technology Enhanced Learning and Social Network Analysis. He published more than 150 scientific papers and is on the editorial board of IEEE Transactions on Technology Enhanced Learning and Social Network Analysis and Mining (SNAM). His research interests are community information systems, multimedia metadata, social network analysis and technology enhanced learning.

Matthias Jarke is Professor of Information Systems at RWTH Aachen University and Director of the Fraunhofer FIT Institute of Applied Information Technology. In his research, he investigates cooperative information systems technologies and applications in business, engineering, and culture. He served as cocoordinator of the DFG-funded German Excellence Cluster on Ultra-Highspeed Mobile Information and Communication (UMIC), and is member of the Fraunhofer Presidential Board with responsibility for the Fraunhofer ICT Group, the largest European research organization in applied IT. Jarke serves on 
numerous editorial board including ACM TMIS, and has chaired the program committees of conferences such as VLDB, EDBT, ECSCW, Mobile HCI, CAiSE, and ER. He is a member of the acatech National Academy of Engineering, and Fellow of the ACM and GI computer societies.

Rynson W.H. Lau received his Ph.D. degree from University of Cambridge. He was on the faculty of Durham University and Hong Kong Polytechnic University. He is now with City University of Hong Kong. Rynson serves on the Editorial Board of Computer Animation and Virtual Worlds and IEEE Trans. on Learning Technologies. He has served as the Guest Editor of a number of journal special issues, including ACM Trans. on Internet Technology, IEEE Trans. on Multimedia, IEEE Trans. on Visualization and Computer Graphics, and IEEE Computer Graphics \& Applications. He has also served in the committee of a number of conferences, including Program Co-chair of ACM VRST 2004, ACM MTDL 2009, IEEE U-Media 2010, ICWL 2014, and Conference Co-chair of CASA 2005, ACM VRST 2005, ICWL 2007, ACM MDI 2009, ACM VRST 2014. His research interests include computer graphics, image processing and multimedia e-learning. 